\title{
A Cloud Platform for the Integration and Optimizing Allocation of High Quality Teaching Resources based on the University-led Collaborative Innovation
}

\author{
Shugang Zhang ${ }^{1}$, Zhenji Zhang ${ }^{1}$ and Xiaolan Guan ${ }^{2 *}$ \\ 1 Beijing Jiaotong University, Beijing 100044, China \\ 2 Beijing Institute of Graphic Communication, Beijing 102600, China \\ \{10113132, zhjzhang,08113101\}@bjtu.edu.cn
}

\begin{abstract}
Collaborative innovation is an important strategy choice of China nowadays, and also of the national universities. Using SOA architecture and cloud computing, we build an integration and optimizing allocation cloud platform of high quality teaching resources for universities-led collaborative innovation to meet the resource requirements of universities based on the analysis of basic concept, types, core process, and evolution characteristics of university-led collaborative innovation following the inherent laws of university-led collaborative innovation, and then analyze the construction concept, logical architecture and main functions of the platform. Finally, we provide a series of suggestions to the relevant universities and government departments to effectively promote the smooth implementation of the university-led collaborative innovation activities and the integration and optimizing allocation cloud platform of high quality teaching resources for university-led collaborative innovation.
\end{abstract}

Keywords: University-led collaborative innovation, High quality teaching resources, Integration and optimizing allocation, Cloud Platform

\section{Introduction}

2011, President Jintao Hu proposed the concept of collaborative innovation in his speech in the 100thanniversary of Tsinghua University from the perspective of constructing an innovative country, emphasizing that every innovation subject of our country should integrate resources according to the strategy need of our country and carry out collaborative innovation activities in order to promote the construction of innovative country [1]. As one of the main subjects of collaborative innovation, the university is not only an important base for the cultivation of high-level innovative talents, but also an important source of basic research and high-tech innovations. The collaborative innovation between universities has great significance to comprehensively improve the quality of higher education, implement the innovative capacity enhancement program of universities, and promote sound and rapid development of collaborative innovation, especially to promote the institutionalization and normalization of collaborative innovation in universities. Therefore, our national universities should build an integration and optimizing allocation platform $\mathrm{f}$ high quality teaching resources to serve the university collaborative innovation following the inherent laws of collaborative innovation, which focuses on the mechanism reform on the basis of key discipline construction, takes the innovation capacity enhancement as a breakthrough and aims at meeting the significant demand of cutting-edge science and national development, and make full use of university resources, brought together a number of universities and institutes to create a new collaborative innovation mode composed of multi-body in order to 
enhance the innovative ability of our national universities and then improve their innovation performance.

Currently, the research on the integration and optimizing allocation of high quality teaching resources in universities can be summarized as the following two aspects, namely the basic theory research and application research.

(1) Basic theory research. The research on the basic theory of integration and optimizing allocation of high quality teaching resources in universities, especially the core issue about how to integrate and allocate the high quality teaching resources in universities is the theoretical foundation of other research directions, and it is also the most essential understanding to the integration and optimizing allocation of high quality teaching resources in universities, which mainly includes the research on the objects, methods, approaches, mechanisms, and efficiency etc. of the integration and optimizing allocation of high quality teaching resources in universities. For example, John f. Ryan analyzed the factors that affect the students' graduation rate by establishing multiple linear regression models, and then put forward a reasonable resource allocation tendency [2]; While Sinunay-Stern[2], Breu and Raab[3]built models using DEA method to evaluate the efficiency in order to optimize the allocation of education resources in universities. In addition, some scholars also used the method of stochastic frontier, statistical classification etc.to optimize the allocation of education resources, and studied the conflict problems in the resources allocation within the universities [5-8]. This kind of research is very important, and there has been lots of this kind of research. However, the research on the basic theory of integration and optimizing allocation of high quality teaching resources in universities still mainly concentrates on the macro level, and emphases on the perception or a small number of qualitative research. The research is not thorough enough, and most of them float on the surface, so it is difficult to guide the specific practice.

(2) Application research. In recent years, more and more scholars began to focus on the construction research of integration and optimizing allocation platform of high quality teaching resources in universities [9-11]. For example, Na Meng and Hamming Long discussed the design, rationality and effectiveness of Yuelushan University City's higher education resources sharing platform, in the 'Construction of teaching resources sharing platform of Yuelushan University' Higher Education'[12].In addition, many scholars also gradually introduced collaborative innovation theory into university development [13]. For example, Jin Chen etc. proposed an industry-university collaborative innovation mode, which realized the overflow of innovation from the university to the enterprise with the output of technology and knowledge of university, and the effectively absorb of companies [14].This kind of research is the latest hotspot both at home and abroad nowadays. However, in terms of functions, most of these platforms just achieve the integration of high quality teaching resources between the universities, they do not have an auxiliary function to facilitate the collaborative innovation between the universities. Meanwhile, they can only realize the resources interaction between some universities, and lack of a comprehensive high quality teaching resources integrating and optimizing allocation service for the innovation development need of all the universities.

Therefore, we intend to use the theory and method of collaborative innovation to analyze the concept of integration and optimizing allocation of high quality teaching resource for university-led collaborative innovation, and then build an information platform that meet both the requirements of integration and optimizing allocation of resources and the collaborative innovation in universities. We are going to provide a series of effective countermeasures for related universities and government departments to carry out the collaborative innovation activities. 
The organization of this paper is as follows. In Section 2, we analyze the basic concept, types, core process, and evolution characteristics of university-led collaborative innovation, and build a system framework for the university-led collaborative innovation; Then, in Section 3, we build a cloud platform for the integration and optimizing allocation of high quality teaching resources for the university-led collaborative innovation, and analyze the construction concept, logical architecture and main functions of the platform; Finally, in Section 4, we provide a series of suggestions to the relevant universities and government departments to effectively promote the smooth implementation of the university-led collaborative innovation activities and the integration and optimizing allocation cloud platform of high quality teaching resources for university-led collaborative innovation.

\section{The Connotation of University-led Collaborative Innovation}

\subsection{The Concept and Types of University-led Collaborative Innovation}

The university-led collaborative innovation is a new paradigm of technological innovation nowadays, which promotes universities and research institutes to play their respective advantages, integrate complementary resources, achieve the interaction of each party's advantage, and accelerate knowledge innovation, application promotion and industrialization. It can be summarized from the microscopic point of view that in order to achieve the common goal, different innovation subjects cooperate, collaborate and consolidate with each other, play to their advantages, obtain external effects, and thus have an effect that 'the total effect of the joint is better than the sum of individual effect', namely $1+1>2$, thereby reduce the university innovation cost and improve the university innovation performance at the same time [15].Specifically, the university-led collaborative innovation refers to that according to the important strategic needs of our country or major scientific and technological projects, the disciplines within the universities, the universities, or the teachers in universities and researchers in scientific research institutions input their superior resources and capabilities together in order to solve the crucial and common technology problems in industries as well as the major issues in actual productions. Under the collaborative support of government and other related subjects, they tackle key problems for teamwork to seek to make significant progress and breakthroughs in scientific research and technology development. 1.

There are diverse types of university-led collaborative innovation, as shown in Figure
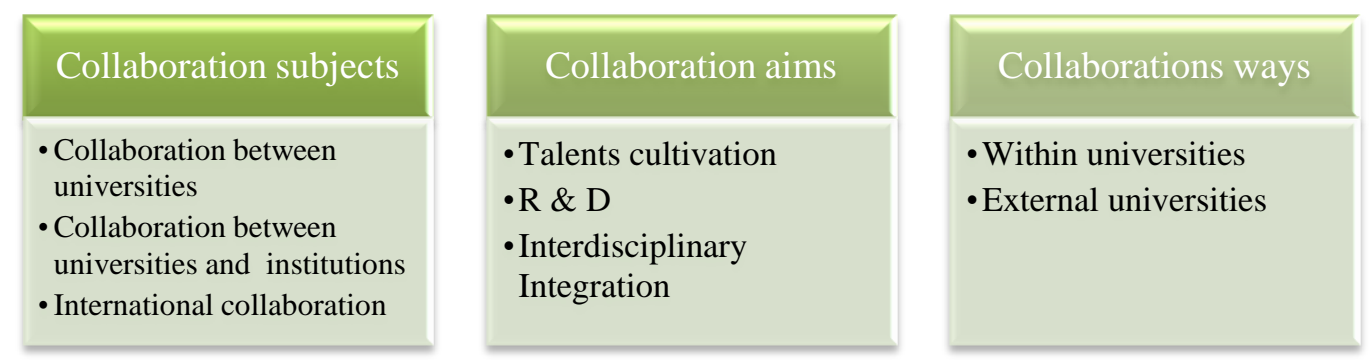

Figure 1. The Types of University-led Collaborative Innovation

\subsection{The Core Process of University-led Collaborative Innovation}

The university-led collaborative innovation is a dynamic process, and an effective aggregation of high quality teaching resources and elements in universities. By breaking the barriers between universities, it can fully release their human, capital, information, 
technology and other innovative resources to achieve cooperation deeply. It is the collaboration of 'Strategy-Resource-Organization', as shown in Figure 2 [16].

The collaboration of strategy, organization and resource is a trinity, and they are inter-conditional. They promote each other and have a dialectical and unified relationship. Here, collaboration of strategy is the basis. Collaborative innovation between universities requires collaboration of strategy. First, it contains the collaboration of values and culture in universities, followed by the collaboration of vision based on trust and communication, and the third is the collaboration of risk and benefits. Collaboration of organization is the guarantee. University-led collaborative innovation involves various main innovation bodies that have different interest objectives. It is a unique hybrid inter-organizational relationship that means a single organization can't get full control of cooperation. Therefore, it needs to have new management skills and organizational design capability, that is to build a cross-border organization at a higher level, such as the specialized collaborative innovation management agency, so that the works of collaborative innovation between universities would have a formal and professional organizational management model. Collaboration of resource is the core. It is the core of university-led collaborative innovation activities, and it's also the transfer, absorption, digestion, sharing, integration, utilization and recreation of high quality teaching resources between universities. It is essentially a process of conversion and upgrade of intangible resources and physical resources that each university owns. Collaboration of resource contains more than one feedbacks and loops. It is a storm-type recombinant of the resource flow among universities.

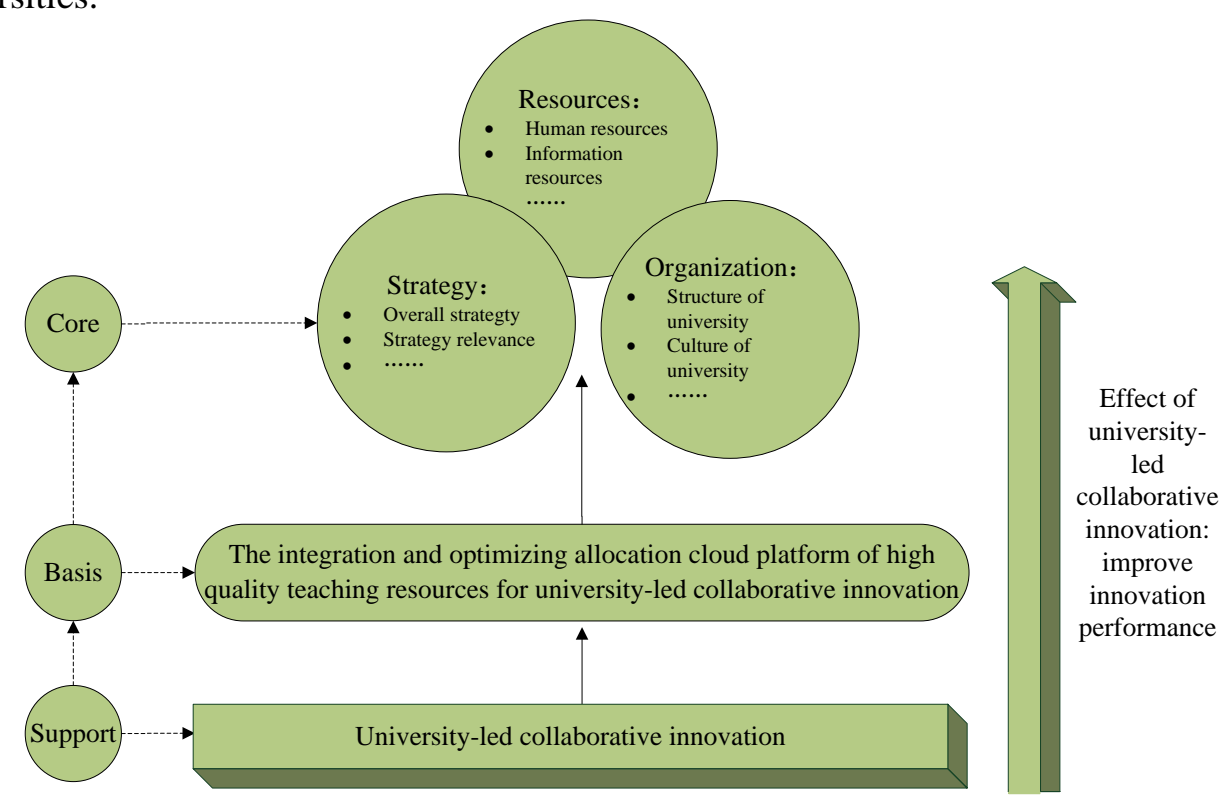

Figure 2. The Process of University-led Collaborative Innovation

\subsection{The Evolution Characteristics of University-led Collaborative Innovation}

The university-led collaborative innovation is composed by numerous subjects, and it has the evolution characteristics of competitive, integration, open, and fluctuation etc., as shown in Figure 3, which build a criss-cross universities-led collaborative innovation network.

(1) Competitive

The relationship between the subjects of university-led collaborative innovation is both competitive and cooperative. If cooperation is more than competition, the coupling degree of university-led collaborative innovation will be low, or even there is no coupling occur; While if the competition is less than cooperation, there will be a high degree of coupling. 
And the improvement of the coupling of the cluster, namely the improvement of mutual adaptation between main subjects in the cluster, can avoid excessive and vicious competition between subjects of university-led collaborative innovation, and thus create a powerful overall force to respond to and participate in the external competition.

(2) Collaborative and integration

There is synergy during the information exchange and resources sharing between subjects (consciously and unconsciously), and it emphases that the university-led collaborative innovation is the ability of overall level, rather than the innovation of a single university. With the emergence of university-led collaborative innovation network, the ability of collaborative innovation is no longer confined to one university, and the innovation extends to innovation node to every university. The innovation mode shifts from the linear innovation to network innovation, and the innovation sources also spread to every university.

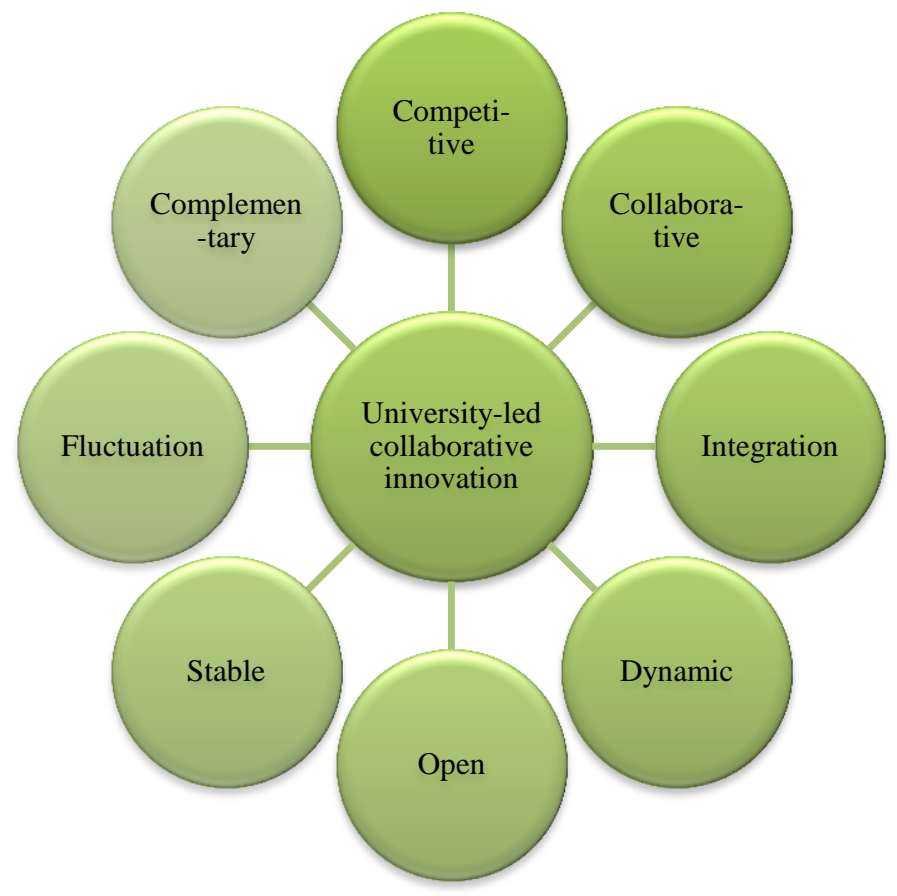

Figure 3 The Evolution Characteristics of University-led Collaborative Innovation

\section{(3) Dynamic}

It refers to the ability of integrating and restructuring innovation resources in order to adapt to changes in the environment, which reflects the nature of the resources and capabilities change with the corresponding changes in the external environment, and it makes up for the static deficiencies of resource-based theory.

(4) Open and stable

There is no border in the exchange of knowledge, including both inside and outside the cluster, which requires the university-led innovative collaborative is open. Non-balance is the requirement of system openness. The architecture of open system in a non-equilibrium state gradually becomes orderly because of the influence outside. Only continue to create new value, and then some features or performance can be broken, that is to say, the science and technology system and technical structure which the reform is in will react to the university-led collaborative innovation and break its equilibrium state. In short, the persistence of non-equilibrium promotes the continuous development of innovation.

(5) Fluctuation 
Fluctuation reflects in the following two aspects. One is that since the key universities have to face fierce competition of market and the long-term and complexity of technological innovation, so the universities must continue to maintain the vitality of innovation, constantly look for the gap between their own shortcomings and other advanced innovative subjects, and form internal driving force for innovation in order to remain competitive advantage, which constitutes an innovative fluctuation phenomenon. And the other one is that the environment is ever-changing and nowhere unchanged, including the market environment, technology and policy environment, they are all volatile, so the operation of university-led collaborative innovation will be affected by these environmental changes inevitably, and thus constitutes another innovation fluctuation.

(6) Complementary

The subjects of collaborative innovation form the university-led collaborative innovation through the coupling of value chain, and their functions in innovation networks are quite different, but complementary. Generally, the university-led collaborative innovation can deal with the long-term of technology and the uncertainty of market, since that it is a positive interaction between geographic accumulation of innovation and innovation outputs. The subjects of the organization and system design of collaborative innovation should consider maintaining the balance between knowledge spillovers and its control.

\section{Design of the Integration and Optimizing Allocation Cloud Platform of High Quality Teaching Resources for University-led Collaborative Innovation}

\subsection{The Construction Concept of the Platform}

The realization of university-led collaborative innovation needs the support of information technology platform to accelerate the effective flow and integration of all kinds of high quality teaching resources between universities. So the integration and optimizing allocation cloud platform of high quality teaching resources for university-led collaborative innovation can not only realize the interconnection of existing sharing platform of high quality teaching resources among universities, and promote barrier-free flow and collaboration allocation of resources on the collaborative innovation value chain, but also can provide collaborative technical support and service for the further cooperation of university-led collaborative innovation on the basis of integration and optimizing allocation of high quality teaching resources in universities, and thus promote the smooth development of collaborative innovation activities. In other words, the platform should be both an integration and optimizing allocation platform of resources, and also a collaborative innovation work system.

Therefore, the design of the platform should be distributive, cooperative and adaptive in order to achieve the interoperability among existing heterogeneous information systems of each university, and realize the cross-system integration and optimizing allocation of high quality teaching resources, and thus effectively meet the needs of communication and interaction between the suppliers and demanders of high quality teaching resources and promote networking transmission of the resources for both sides. Meanwhile, according to the resource needs arising from the main innovation subjects during the collaborative innovation cooperation, it can provide the required high quality teaching resources and integration services timely and accurately.

Thus, we propose the construction concept of the integration and optimizing allocation cloud platform of high quality teaching resources for university-led collaborative innovation, as shown in Figure 4. 


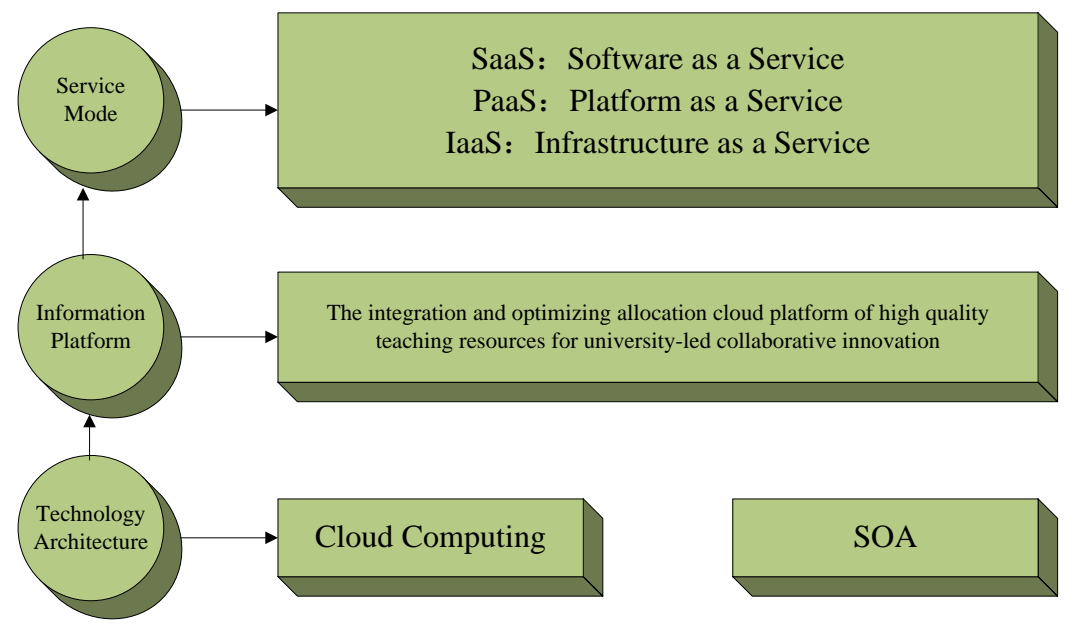

\section{Figure 4. The Construction Concept of the Integration and Optimizing Allocation Cloud Platform of High Quality Teaching Resources for University-led Collaborative Innovation}

\subsection{The Logical Architecture of the Platform}

According to the above analysis of the construction concept, we design the logical architecture of the integration and optimizing allocation cloud platform of high quality teaching resources for university-led collaborative innovation, as shown in Figure 5.The logical architecture of the platform is designed according to the design principles of progressiveness, good adaptability to the network environment, unified external data interface, comprehensive data storage, backup management strategy, high security, reliability and stability, ease of operation, flexibility and scalability, component-based software development, and technical data sharing and so on. The entire platform architecture uses a hierarchical and distributed deployment architecture, which is divided into six layers, namely the basic layer, implementation layer, application layer, access layer, security layer and management layer. It can ensure the consistency and stability of the application service logic, openness of the structure, scalability and maintainability of the function, and the parallelism of the development by separating the application layer and implementation layer. 


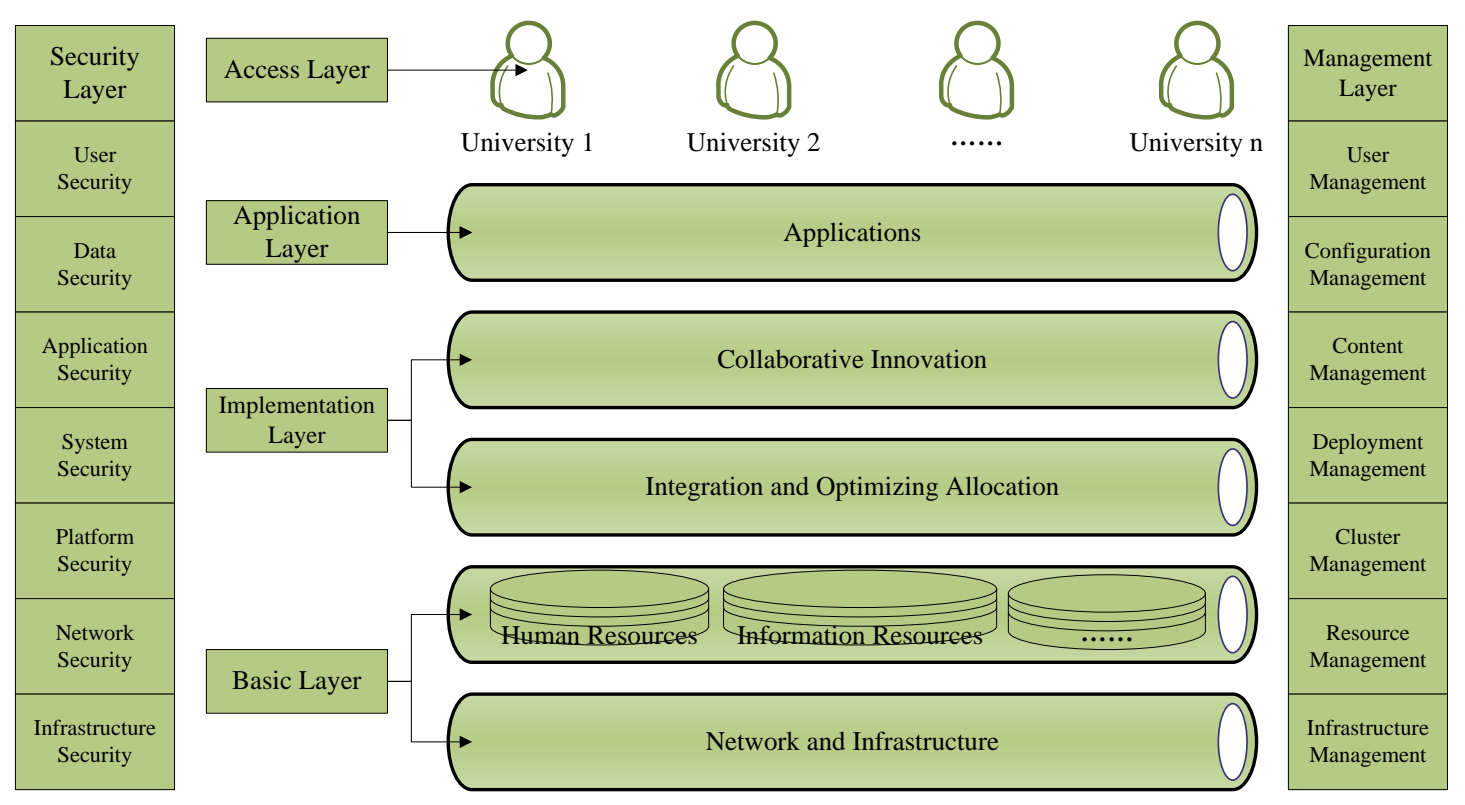

The integration and optimizing allocation cloud platform of high quality teaching resources for university-led collaborative innovation

\section{Figure 5. The Logical Architecture of the Integration and Optimizing Allocation Cloud Platform of High Quality Teaching Resources for University-led Collaborative Innovation}

(1)Basic layer

This layer is the basic condition to support the running of the platform, mainly including the following three aspects, namely the network infrastructure, technical support environment and management mechanism. In addition, it also includes the high quality teaching resources that are distributed stored and other network resources servicing for the integration and optimizing allocation of high quality teaching resource in universities. Due to the heterogeneity of high quality teaching resources, the resource layer needs to apply metadata standard on the unified specification description of these resources, and provides appropriate access interface to metadata and physical data, then uses the Web Service technology to encapsulate data access interface for external systems call.

(2)Implementation layer

This layer is the core of the integration and optimizing allocation cloud platform of high quality teaching resources for university-led collaborative innovation, which undertakes the task of technical realization of entire integration and optimizing allocation and collaborative innovation work. First, according to the characteristics of distribution, heterogeneity and autonomy, this layer integrates high quality teaching resources stored in different information systems by means of resource encapsulation, format conversion and data mapping, and establishes a high-level resource sharing database, in order to provide resource guarantee for collaborative innovation between innovative universities, and then achieves the optimizing allocation of high quality teaching resources by the functions of description, discovery, optimization, matching and dynamic invocation of high quality teaching resources. Meanwhile, it also provides a unified interaction platform for collaborative innovation among universities, using kinds of collaborative technologies and tool software to service innovation cooperation among universities. The universities can use Web2.0 and other collaborative communication 
tools to send instant message, and can also take advantage of the population sensing technology and collaborative control technology to call resources needed for innovation to cooperate, complete the collaborative innovation links via various types of collaborative software, and thus truly realizes the organic combination of integration and optimizing allocation of high quality teaching resources and collaborative innovation.

(3)Application layer

This layer encapsulates the technology and application interface of the layer of integration and optimizing allocation of high quality teaching resources, and provides users integrated services by a unified system interface. This layer includes collaborative innovation platform, high quality teaching resources sharing platform, workflow platform, resource management platform and information service platform.

(4)Access layer

The users of the integration and optimizing allocation cloud platform of high quality teaching resources for university-led collaborative innovation are mainly the universities. However, they are not just the users of the platform, they are also builders. They need to expand the scope of sharing through resource network, improve the utilization value of the resources under the government's overall planning. During the integration and optimizing allocation process of high quality teaching resources, the universities can use the platform to get the resources they need according to their resource requirements under the supervision of the relevant regulatory agencies.

(5) Security layer

The security layer is responsible for the security of the entire integration and optimizing allocation cloud platform of high quality teaching resources for university-led collaborative innovation, including infrastructure security, network security, platform security, system security, application security, data security and user safety from bottom to top, and thus form a layered defense system.

(6) Management layer

The management layer is responsible for the operation and configuration management of all the entire integration and optimizing allocation cloud platform of high quality teaching resources for university-led collaborative innovation, including resource management, network monitoring, cluster management, deployment management, content management, configuration management, and user management. It monitors the health of the entire cloud platform at all levels, optimize the allocation of resources, and thus improve the overall resource efficiency.

\subsection{The Main Functions of the Platform}

According to the construction concept and the logical architecture design of the integration and optimizing allocation cloud platform of high quality teaching resources for university-led collaborative innovation, the main functions of the platform are shown in Figure 6.

(1)Rights management

The integration and optimizing allocation cloud platform of high quality teaching resources for university-led collaborative innovation takes a series of measures to provide protection for the safe use of informationandquality teaching resources for the users, such as rights assignment, digital certification and other access authentications.

(2) Catalog management

The integration and optimizing allocation cloud platform of high quality teaching resources for university-led collaborative innovation will provide a shared directory management to recordresources stored in each node, and manage the aggregated directory informationof each node in the central node in order to facilitate the management and query to the distributed highquality teaching resources. 


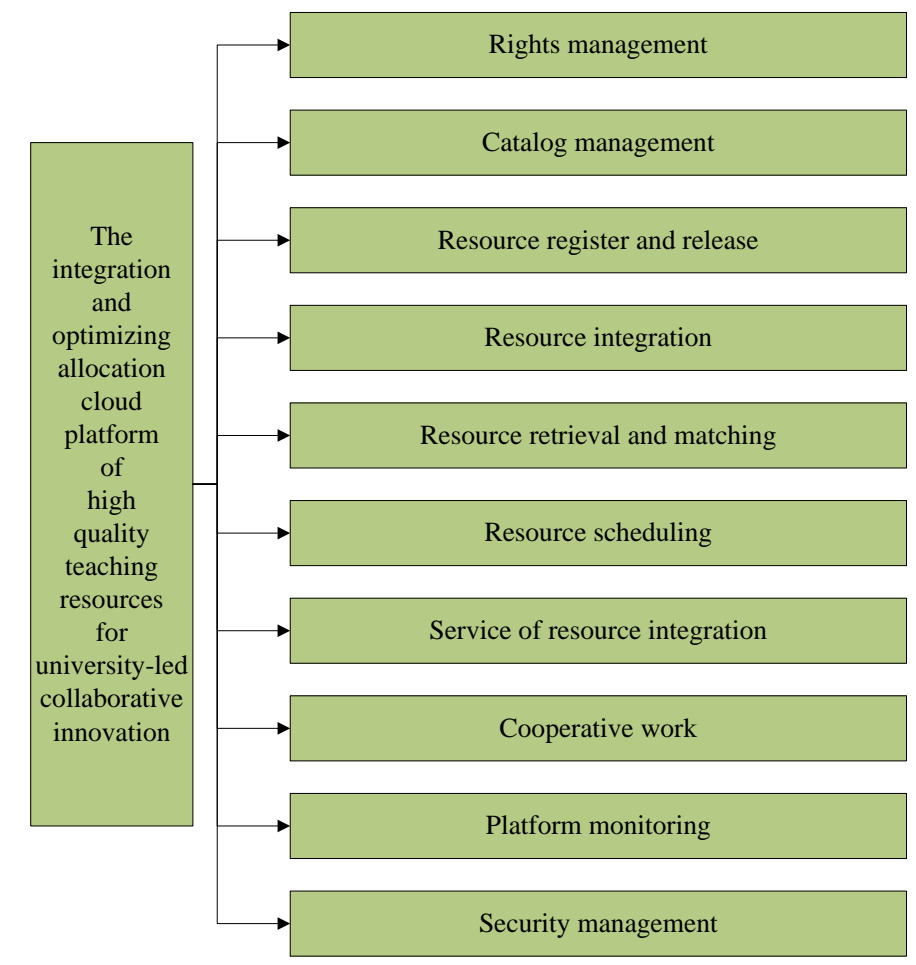

\section{Figure 6. The Main Functions of the Integration and Optimizing Allocation Cloud Platform of High Quality Teaching Resources for University-led Collaborative Innovation}

\section{(3) Resource register and release}

The function of resource register and release aims to achieve the registration management and precise positioning of distributed high quality teaching resources. The universities can describe the information about the resource (such as its name, category, source, property, etc.) by a unified resource description specification, and then provide registration management and indexing service about the network resources through resource registry meta-service. The function of resource release not only allows the universities to provide information abouttheir own high quality teaching resources, but also can release various needs information on the platform, so as to realize the resource cooperation between universities.

(4)Resource integration

This is one of the main functions of the integration and optimizing allocation cloud platform of high quality teaching resources for university-led collaborative innovation. It aimsto realize the integration of distributed high quality teaching resourcesin different information systemsusing external coordinationtechnology,middleware technology, interoperability technology,standard protocol, and semantic collaborative,etc. Then establish a data acquisition adapter service system to collect data from different sources, and integrate and classify the integrated resources, and store them in the sharing database. The data then can be used for each university in collaborative innovation activity.

(5)Resource retrieval and matching

The integration and optimizing allocationcloudplatform of high quality teaching resources for university-led collaborative innovation provides transparent access todistributed heterogeneous data through data integration and aggregation technology. The users can get access to the integratedhigh quality teaching resources through keyword matching and semantic search way, etc. Resource retrieval mechanism and aggregation of the allocation of requests and results are the two core issues of resource retrieval.And they can be achieved through resource retrieval agent and service aggregation. Platform can 
match the users'descriptionof request resource with the description of released resources in order to get a set of resources that meet the needs.

(6)Resource scheduling

This function can realize dynamic scheduling and allocation of resources usingcorresponding resource scheduling algorithm. Itgenerally can be divided into three stages, namely resource discovery, resource selection and task execution. Here, the resource selection is a key step of scheduling, and it is one of the core features of integration and optimizing allocationcloudplatform of high quality teaching resources for university-led collaborative innovation. The function of resource selection is to chooseareasonable resource collection from a set of available resources according to determined task requirements in order to minimize the task execution time. It can maximum satisfy the real-time demand of universitiesthrough dynamic resource scheduling and allocation, and thus improve the efficiency of innovation.

(7)Service of resourceintegration

The service of resourceintegration includes a series of service functions, such as resource release, user feedbackprocess, expert system, resource integration and retrieval, resource recommendation, resource navigation, and special advisory services, etc. Its main function is to integrate high quality teaching resources and servicesin universities that distribute in different geographical positions, and then discover, analyze and call all needed resources and services according to theneeds ofusers, andfinally organize the integrated service in accordance with the personalized service process and business logic flexibly.It can provide one-stop service for universities.

(8) Cooperative work

Cooperative work is one of the core functions of the integration and optimizing allocation cloud platform of high quality teaching resources for university-led collaborative innovation. In the environment of the integration and optimizing allocation platform of high quality teaching resources, the universities that distribute in different places canrealize cooperation about knowledge innovation and technology innovation on this platformusing a variety of collaborative software tools (such as OA, collaborative management software etc.) and collaborative technologies (such as role-based collaboration, information cooperation, process collaboration, collaborative technology calculation etc.).The collaborative workmainly uses workflow technology to realize the business process running of innovationsubjects, support centralized control and management of the business processesbetter, and thus promote the organic interaction between the various linkson the innovation value chain effectively.

(9)Platform monitoring

The integration and optimizing allocation cloud platform of high quality teaching resources for university-led collaborative innovation will carry out a comprehensive monitoron the basic layer, implementation layer, application layer, access layer, security layer and management layerto ensure the normal operation of the cloud platform, and the effectiveness and availability of resources.

(10) Security management

It will guarantee the whole security of the integration and optimizing allocation cloud platform of high quality teaching resources for university-led collaborative innovation by using safety-related technologies on the physical layer, data layer and application layer.

\section{Implementation Safeguards of the Integration and Optimizing Allocation Cloud Platform of High Quality Teaching Resources for University-led Collaborative Innovation}

In order to implement the '2011 plan', and promote the university-led collaborative innovation actively, the government should encourage the universities to carry out deep cooperation and establish strategic alliance between universities by mechanism 
innovation and policy guidance. The universities also should make collaborative innovation strategy plan according to their own advantage and development orientation, handle the relationship with other universities properly, build collaborative innovation platform actively, establish the talent cultivation zone which stresses top-notch cultivation of innovation talent, and thus build a full range of collaborative innovation environment.

(1)Establish a new concept of university-led collaborative innovation.

The university should introduce the concept of collaborative innovation into the practice of talent cultivation, scientific research and social service, highlight the important position of innovation in educational philosophy, and emphasize 'cooperation' as an important content of the educational philosophy of university. The university can establish cooperative innovation community that is open, integrated and efficient with scientific research institutes, enterprises, government or other international communities around the superior discipline group, meet the needs of our country, solve the major scientific problems, and thus contribute to the construction of our national innovation system.

(2) Fully understand the importance of the integration and optimizing allocation of high quality teaching resources in universities, and strengthen the top-level design and system planning for the university-led collaborative innovation in order to tap new sources of supply and reduce consumption.

The government should formulate policies and regulations to encourage or attract input from social resources to teaching resources in order to tap new sources of limited resources supply under the premise of limited government teaching resources investment. Meantime, the government also should strengthen the top-level design and system planning for the integration and optimizing allocation of high quality teaching resources in universities to achieve sharing of limited resources by means of information technology, and thus reduce resource consumption.

(3)Optimize the realization form of university-led collaborative innovation, and build an incentive mechanism for university-led collaborative innovation.

In order to get a formal and professional management model for university-led collaborative innovation, we need to build an effective system of organization and management, including the establishment of a special university-led collaborative innovation management mechanism. Meantime, the government department that is relevant should provide security services and policy support for universities. They should consider the input intensity and practical innovation contribution of each university, and then design a reasonable profit distribution scheme in order to encourage and support university-led collaborative innovation.

\section{Conclusions}

To strengthen the integration and optimizing allocation of high quality teaching resources for university-led cooperative innovation is not only conducive to break the closed consciousness of each university and improve the utility efficiency of resources, but also can tap the existing potential of universities, enhance the cooperative innovation concept and improve innovation performance of universities. We built an integration and optimizing allocation cloud platform of high quality teaching resources for universities-led collaborative innovation to meet the resource requirements of universities based on the analysis of basic concept, types, core process, and evolution characteristics of university-led collaborative innovation following the inherent laws of university-led collaborative innovation using SOA architecture and cloud computing, analyzed the construction concept, logical architecture and main functions of the platform, and finally we provided a series of suggestions to the relevant universities and government departments to effectively 
promote the smooth implementation of the university-led collaborative innovation activities and the integration and optimizing allocation cloud platform of high quality teaching resources for university-led collaborative innovation.

\section{Acknowledgements}

This work was partially supported by the Quality ImprovementProjectof Personnel Training of Beijing Municipal Education Commission (No. 03150113016), the grant from the Major Program of Beijing Planning office of Philosophy and Social Science (No. 13ZDB10), and the Course Construction Projectof Beijing Institute of Graphic Communication (No. 22150112088).

\section{References}

[1] J. Hu, "The speech in the 100th anniversary of Tsinghua University", China Higher Education, vol. 9, (2011), pp.4-6.

[2] J. F. Ryan, "The Relationship between Institutional Expenditures and Degree Attainment", Research in Higher Education, vol. 45, no. 2, (2004), pp.97-115.

[3] A. Colbert, R. R. Levary and M. C. Shaner, "Determining the Relative Efficiency of MBA Programs Using DEA", European Journal of Operational Research, vol. 125, (2000), pp.656-669.

[4] T. M. Beru and R. L. Raab, "Efficiency and Perceived Quality of the Nations 'TOP' National Universities and National Liberal Arts Colleges: An Application of Data Envelopment Analysis to Higher Education”, Socio-Economic Planning Science, vol. 28, (1994), pp. 33-45.

[5] Y. Huang and Q. Liu, "Study on Current Situation and Countermeasures of DigitalEducational Resources Integration in University", Journal of Modern Information, vol. 31, no. 9, (2011), pp.67-70.

[6] X. Sun, "Study on the Effectiveness of Educational Resources Integration in University", Heilongjiang Education (Higher Education Research \& Appraisal), vol. 3, (2007), pp.7-8.

[7] L. Jia, "TheIntegration and Optimization of Teaching Resources in Beijing University of Chemical Technology", Beijing University of Chemical Technology, (2008).

[8] Y. Li, "Research on Educational Resources Integration for Industrial CitiesinHeilongiang Province", HarbinEngineeringUniversity, (2006).

[9] Y. Wang, "Research and Practice of Education Information Integration Platform Based on Service Oriented Architecture", Science Mosaic, vol. 6, (2010), pp. 77-79.

[10] X. Xu and X. Su, "Research on Digital Resource Integration Platform of University", vol. 9, (2005), pp. 62-69.

[11] P. Duan, "Study and Implement on Agent-Based EducationResource Purvey System", Northeast Normal University, (2005).

[12] N. Meng and H. Long, "Construction of teaching resources sharing platform of Yuelushan University' Higher Education", Times Finance, vol. 2, (2009), pp. 63-65.

[13] H. Chen, Q. Zhao and Z. Jin, "Study on grey evolutionary Game of "Industry-University-Institute", Cooperative Innovation, Proceedings of IEEE International Conference on Grey Systems and Intelligent Services, Nanjing: Nanjing University of Aeronautics and Astronautics, (2009).

[14] J. Chnen and W. Ye, "The modes of university-industry collaborative innovation in service: A case study from China", Proceedings of the 4th IEEE International Conference on Management and Service Science, (2010); Wuhan.

[15] Z. Zhou, "Study on the Synergic Innovative Networks from the perspective of Economics", Jilin University, (2013).

[16] Y. Xiang, "The Process Mechanism of University-IndustryCollaborative Innovation based on KnowledgeTriangle", Zhejiang University, (2013). 
International Journal of Grid Distribution Computing Vol. 8, No. 1 (2015) 